\title{
Constraints in implementation of pedigree and performance recording practices at field level in Pakistan
}

\section{Opinion}

Pakistan is rich in Animal Genetic Resources having a huge population of cattle, buffalo, sheep and goat with approximate population of 180 million. Most of the cattle breeds have low production potential except Sahiwal, Red Sindhi and Cholistani breeds which are basically kept as dairy breeds. Among buffalo breeds found in Pakistan, Nili Ravi breed is one of the best dairy animals. Although these dairy cattle and buffalo breeds have good potential but their rear genetic potential has not yet been exploited. Constraints in implementation of pedigree and performance recording practices at field level in Pakistan have been briefly enlisted in this communication. Livestock sector in Pakistan plays a very important role in the economy and it has become the back bone of agriculture sector since last few years. Energy crises in Pakistan have significantly affected cotton industry and has diverted the attention of investors towards livestock sector. Pakistan is rich in Animal Genetic Resources having a huge population of cattle, buffalo, sheep and goat with approximate population of 180 million. Most of the cattle breeds have low production potential except Sahiwal, Red Sindhi and Cholistani breeds which are basically kept as dairy breeds. Among buffalo breeds found in Pakistan, Nili Ravi breed is one of the best dairy animals. Although these dairy cattle and buffalo breeds have good potential but their rear genetic potential has not yet been exploited. Most of the local breeds are resistant to diseases can tolerate hot and humid climatic conditions and have a very good tick resistance. Genetic improvement programs for Sahiwal, Cholistani cattle and Nili Ravi buffalo breeds have been started in recent years at farmer's level but rest of the breeds still need attention of policy makers.

There is no system of record keeping at farmer's level. The efforts by the Govt. to establish a pedigree and performance recording system at field level have never been succeeded. Proper record keeping provides the basis for improvement in production and reproductive performance of dairy cattle and buffaloes. Most important use of pedigree and performance records is in making selection and breeding decisions. Genetic improvement is not possible without developing a sound pedigree and performance recording system. Some of the constraints regarding implementation of pedigree and performance recording practices at field level in Pakistan include small holding dairy production system rather one man one cow system, illiterate
Volume 6 Issue 2 - 2017

\author{
Riaz Hussain Mirza \\ Faculty of Veterinary Sciences, Bahauddin Zakariya University, \\ Pakistan
}

Correspondence: Riaz Hussain Mirza,Assistant Professor, Faculty of Veterinary Sciences, Bahauddin Zakariya University, Multan, Pakistan, Email riazmirza7। @yahoo.com

Received: December 03, 2017| Published: December 14, 2017

farmers community, political factors regarding implementation of recording system at farmers level, lack of technical knowledge specially with reference to progeny testing program, misconceptions regarding implementation of progeny testing program, poor feeding and management practices, no incentives to farmers to facilitate record keeping, fake records even if available, uncertainty regarding development projects, lack of data processing centers specially with references to genetic evaluation, estimation of breeding values and ranking of cows/buffaloes on the basis of their genetic potential, limited allocation of resources by the govt. for development and implementation of progeny testing program. Recently, first herd book of Sahiwal cattle breeders have been published in Pakistan. Well organized Farmers associations and breeders societies at their own level can play a leading role in the development of pedigree and performance recording system. Govt. must facilitate such organizations and should develop a reliable system of record keeping with the help of farmer's community. A central data processing and analysis centre with reference to progeny testing program of Sahiwal cattle and Nili Ravi buffalo breeds must be developed by the Govt. with the help of Sahiwal and Buffalo breeders association of Pakistan.

\section{Acknowledgements}

None.

\section{Conflict of interest}

Author declares that there is no conflict of interest. 